University of South Carolina

Scholar Commons

4-1-2006

\title{
Power Anomaly Effects and Costs in Low-Voltage Mobile Power Systems
}

Shengyi Liu

Boeing, shengyi.liu@boeing.com

Charles H. Singer

NAVAIR

Roger A. Dougal

University of South Carolina - Columbia, dougal@engr.sc.edu

Follow this and additional works at: https://scholarcommons.sc.edu/elct_facpub

Part of the Electrical and Computer Engineering Commons

\section{Publication Info}

Published in IEEE Transactions on Aerospace and Electronic Systems, Volume 42, 2006, pages 612-624. http://ieeexplore.ieee.org/xpl/Recentlssue.jsp?punumber=7

(C) 2006 by IEEE

This Article is brought to you by the Electrical Engineering, Department of at Scholar Commons. It has been accepted for inclusion in Faculty Publications by an authorized administrator of Scholar Commons. For more information, please contact digres@mailbox.sc.edu. 


\section{Power Anomaly Effects and Costs in Low-Voltage Mobile Power Systems}

\author{
SHENGYI LIU, Senior Member, IEEE \\ University of South Carolina \\ CHARLES H. SINGER \\ NAVAIR \\ ROGER A. DOUGAL, Senior Member, IEEE \\ University of South Carolina
}

Electric power anomalies or disturbances can disrupt the normal operation of equipment, accelerate aging, or even cause outright failures thus resulting in increased costs of maintenance and reduced system reliability. Past research on the effects caused by power anomalies has been mostly focused on industrial, commercial, or residential systems, or on power distribution equipment. A literature survey reveals that there is no comprehensive review related to low-voltage $(\mathrm{LV})$ power systems and utilization equipment applicable to military combat vehicles, such as aircraft and ships. This paper summarizes the results of a new literature survey that focused on the causes, effects, and mitigation methods for power anomalies typical of $\mathrm{LV}$ mobile power systems. Electric power anomaly cost data collected from the literature are also presented, from which the costs of anomalies to the national defense are estimated using some simple rationales.

Manuscript received February 22, 2005; revised September 2, 2005; released for publication October 6, 2005.

IEEE Log No. T-AES/42/2/876438.

Refereeing of this contribution was handled by W. M. Polivka.

This work was supported by the U.S. Naval Air Systems Command under Contract N00421-00-D-0154.

Authors' addresses: S. Liu and R. A. Dougal, Dept. of Electrical Engineering, University of South Carolina, Columbia, SC 29208, E-mail: (lius@engr.sc.edu); C. H. Singer, Electric Power System Division, AIR-4.4.4.1, NAVAIR, 48298 Shaw Rd., Patuxent River, MD 20670-1900.

0018-9251/06/\$17.00 (c) 2006 IEEE

\section{INTRODUCTION}

Power anomalies or power disturbances (PDs), whether resulting from natural causes or human errors, from unpredicted incidents or scheduled events, are detrimental to both power distribution and utilization equipment. Depending upon the criticality of the equipment, the consequences can be very costly or even catastrophic. One report [1] shows that power outages and interruptions cost the U.S. economy between $\$ 104$ billion and $\$ 164$ billion a year due to equipment damage, materials loss, idled labor, and lost production or sales, and another $\$ 15$ billion to $\$ 24$ billion a year is lost due to power quality phenomena. The total loss amounts to $1.2 \%$ to $1.9 \%$ of the U.S. gross domestic product (GDP) (in 2001, the U.S. GDP was $\$ 10,100.8$ billion in 2001 dollars [2]). To estimate the costs of power interruptions and disturbances to the national defense industry and services (including military installations, war machines, weapons and space programs, etc.), one simple rationale would be to compare the military spending with the GDP. According to CDI [3], the U.S. total military and military-related spending in 2001 was $\$ 484.3$ billion. This yields a loss to the national defense of $\$ 5.8$ to $\$ 9.2$ billion a year just due to electric PD problems. To improve the estimate, the characteristics of military equipment and power systems must be considered. In general, the PD cost is a function of several system and equipment parameters: the frequency of occurrence of disturbances, the sensitivity of the equipment to disturbances, the expenses of equipment manufacturing and maintenance, and finally, the costs of other consequences due to disturbances. The military equipment is often designed to be robust and thus less sensitive to disturbances. Therefore, the probability of a disturbance event to become disruptive or to cause damaging effect is lower in military equipment. On the other hand, unlike industrial and commercial stationary systems, mobile military systems are subject to disturbances more frequently due to their own operating characteristics, and furthermore, they are often required to work under extreme conditions. In addition, the military equipment is of higher values, and the maintenance is more costly, thus the average cost per disturbance is probably higher than that in the industrial and commercial equipment. However, the data for these parameters are currently not available. Clearly, more studies are needed to improve the estimate.

In military applications, the PD problem is not only an issue of economy, but also an issue of availability. In wartimes, the consequences of a malfunctioning or failed radar system for early-warning of hostile objects can be disastrous, including the loss of lives, or whole battles. It is clear that the cost category in this case extends far beyond the expenses of equipment, labor, and disrupted operations. 
Given the significance of the PD effects and costs, the authors of this paper conducted a literature survey to collect data particularly focusing on the disturbances in low-voltage (LV) power systems applicable to military combat vehicles such as aircrafts and ships. Because the electric power is used to operate computers, control and communication systems (the brains of these war machines) the PD effect is critically important. For all-electric vehicles of the future, it is obvious that the electric power reliability will be critical to the vehicles' survival in battlefields.

In reviewing the collected literature, we noticed that there have been tremendous research efforts on PD effects. However, the majority of the previous work focused on applications for industrial, commercial, residential, and PD equipment. In particular, there is no comprehensive review related to $\mathrm{LV}$ power systems and utilization equipment applicable to military combat vehicles, such as aircraft and ships. The purpose of this paper is to summarize and review the PD effects and cost data gathered from the literature that are typical of LV power systems, thereby estimating the PD costs to military installed electric power systems used in air-, sea- and land-based vehicles. These results are useful for reliability and economic analysis in design and development of PD mitigation methods and technologies.

The nomenclature of disturbance types used in this paper follows the IEEE standard classification [4]. We discuss the disturbances including 1) transients, 2) short- and long-duration voltage variations, 3 ) waveform distortion, 4) voltage imbalance, 5) power frequency variations, and 6) static charge. Broadband noise and electromagnetic interference (EMI) are not discussed here. Whenever possible, the cause, effect, cost, and mitigation method of each type of disturbance is presented based on the literature survey.

\section{CHARACTERISTICS OF LV MOBILE POWER SYSTEMS}

Currently, the electric power systems in combat vehicles primarily power dc electronics such as computers, displays, sensors, control and communication systems; ac equipment such as protection relays, bus ties, valves, actuators, and equipment for lighting, heating, and cooling; and high voltage dc equipment such as surveillance radar, etc. In all-electric combat vehicles of the future, electric power will also be used for propulsion.

The characteristics of electric power systems for military vehicles differ significantly from one to another depending upon scopes and scenarios. We use an aircraft electric power system here as a baseline for our analysis. A typical aircraft LV electric power system is shown in Fig. 1. In this system, the prime mover is the aircraft engine. The main bus from the generator is $3 \phi, 400 \mathrm{~Hz}, 115 \mathrm{Vac}$ (line-to-ground). The auxiliary power unit (APU) provides the starting power to the engine, and the emergency power to the system in case of a failure of the engine or the generator. The onboard battery unit can provide limited power to operate the most critical equipment if the aircraft suffers a loss of ac power. On the load side, power is available for the following load types: 1) $115 \mathrm{Vac}, 400 \mathrm{~Hz}$, 2) $115 \mathrm{Vac}, 60 \mathrm{~Hz}$, 3) $26 \mathrm{Vac}, 400 \mathrm{~Hz}$, 4) $28 \mathrm{Vdc}$, and 5) $270 \mathrm{Vdc}$. The aircraft structure serves as the neutral conductor of the 3-phase power system, the return conductor for the dc loads, and the safety and reference "ground."

In terms of characteristics of operation and power anomalies, several features distinguish aircraft electric power systems from terrestrial utility systems. First, the system start, stop, and voltage transfer, which cause disturbances, are normal operations in aircraft systems, whereas utilities generate power continuously unless a power failure or a scheduled interruption occurs. Secondly, aircraft power systems are autonomous and compact, therefore the effect of disturbances between source and source, source and load, and load and load are more pronounced. Thirdly, aircraft uses a $400 \mathrm{~Hz}$ ac main with multiple $400 \mathrm{~Hz}$ $115 \mathrm{Vac}, 60 \mathrm{~Hz} 115 \mathrm{Vac}, 400 \mathrm{~Hz} 26 \mathrm{Vac}, 28 \mathrm{Vdc}$, and $270 \mathrm{Vdc}$ distribution panels or branches; whereas terrestrial systems use $50 / 60 \mathrm{~Hz}$ in all transmission, distribution, and branch circuits. Fourthly, frequency variation becomes an issue in aircraft systems because of small capacities $(\sim \mathrm{kVA})$ of generators relative to the loads. The issue generally does not exist in terrestrial systems because of the stiffness of the grid, except the backup systems in hospitals and data centers, where small capacity generators are also used. Finally, there are no present terrestrial requirements for distributing dc voltage, whereas aircraft utilizes 28 and $270 \mathrm{Vdc}$ for various systems. Thus dc anomalies must be specifically addressed. Table I lists the comparison of terrestrial and aircraft LV electrical system anomalies, which shows that some of the phenomena are similar, while others such as voltage transfers, ac frequency variations, and dc disturbances, are of different significances in the two systems.

Power anomalies can result from various causes. A brief description of these causes follows.

Disturbances from Power Sources: The amplitude and frequency of the main bus voltage may vary due to change of the engine speed or load torque, or due to instability of the control system. Voltage transfer from a primary feeder to an alternate feeder causes a short-duration voltage sag and a dc offset. A power source failure causes short- or long-duration interruptions.

Disturbances at Power Converters and Distribution Buses: Power converters such as transformer 


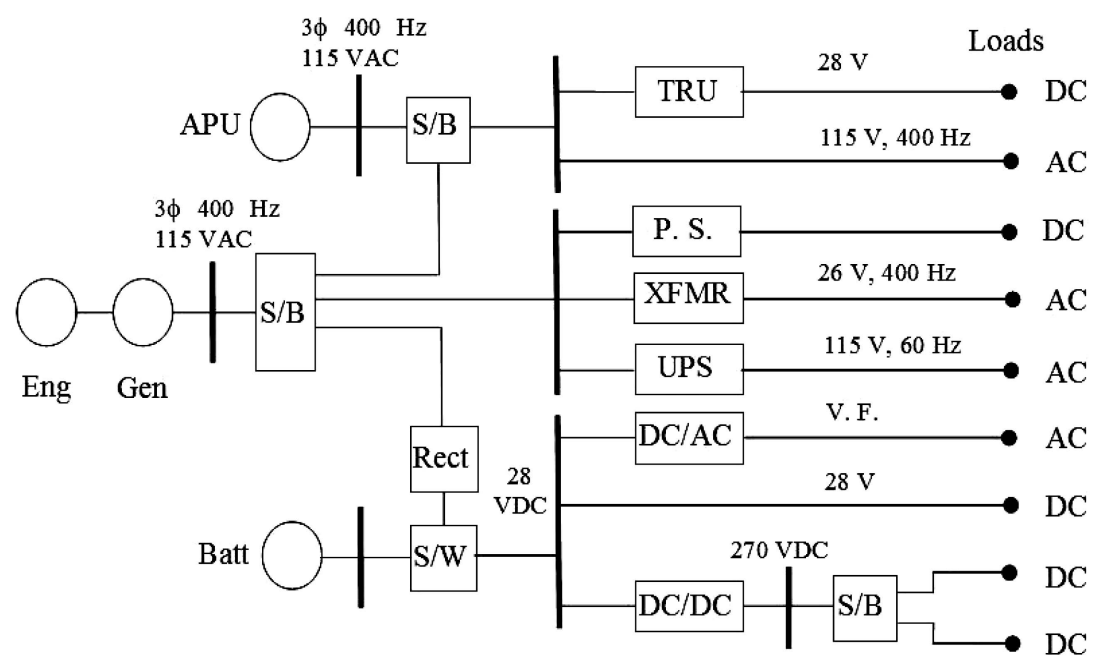

Fig. 1. Typical aircraft LV electric power system.

TABLE I

Comparison of Terrestrial and Aircraft LV Electric System Anomalies

\begin{tabular}{c|l|l|l}
\hline \hline $\begin{array}{c}\text { System } \\
\text { Type }\end{array}$ & \multicolumn{1}{|c|}{$\begin{array}{c}\text { Electric } \\
\text { Anomaly }\end{array}$} & \multicolumn{1}{|c}{$\begin{array}{c}\text { Terrestrial } \\
\text { System }\end{array}$} & \multicolumn{1}{|c}{$\begin{array}{c}\text { Aircraft } \\
\text { System }\end{array}$} \\
\hline \multirow{4}{*}{ AC } & Transients & Yes & Yes \\
& Voltage variations & Yes & Yes \\
& Voltage imbalance & Yes & Yes \\
& Voltage transfers & No & Yes \\
& Frequency variations & No $60 \mathrm{~Hz}$ & Yes 400 Hz \\
& Waveform distortion & Yes & Yes \\
\hline \multirow{3}{*}{ DC } & Voltage variations & Not Addressed & Yes \\
& Voltage transfers & Not Addressed & Yes \\
& Voltage ripples & Not Addressed & Yes \\
\hline \multirow{2}{*}{ Static } & Static buildup & Yes & Yes \\
\hline
\end{tabular}

rectifier units (TRUs), rectifiers, dc/ac and dc/dc converters produce voltage switching transients and harmonic currents, which distort distribution bus voltages, and, further, alter the main bus voltage. Converter components may fail, resulting in tripped circuit breakers, thus causing voltage sags, swells, or interruptions.

Disturbances from Loads: Nonlinear loads such as avionics, computer and communication equipment, motor drives, radar power modulators, and lamp balancing and dimming circuits are the sources of harmonic currents. Unbalanced 3-phase ac loads due to unevenly distributed single-phase loads result in voltage imbalance. A load switch-in or out, a faulty load, a ground fault, or a line-to-line fault can result in local voltage sags, swells, or interruptions.

Disturbances from External Sources: Lightning, electromagnetic pulses (EMPs) from nuclear detonations, static buildup due to atmospheric electricity, etc., can cause interference and interruptions.
TABLE II

Transients [4]

\begin{tabular}{l|l|l|l|l}
\hline \hline \multicolumn{2}{c|}{ Categories } & Spectrum & Duration & Magnitude \\
\hline \multirow{4}{*}{ Impulsive } & Nanosecond & $5 \mathrm{~ns}$ rise & $<50 \mathrm{~ns}$ & \\
& Microsecond & $1 \mathrm{us}$ rise & $50 \mathrm{~ns}-1 \mathrm{~ms}$ & \\
& Millisecond & $0.1 \mathrm{~ms}$ rise & $>1 \mathrm{~ms}$ & \\
\hline \multirow{3}{*}{ Oscillatory } & Low frequency & $<5 \mathrm{kHz}$ & $0.3-50 \mathrm{~ms}$ & $0-4$ p.u. \\
& Med. frequency & $5-500 \mathrm{kHz}$ & $20 \mathrm{us}$ & $0-8$ p.u. \\
& High frequency & $0.5-5 \mathrm{MHz}$ & $5 \mathrm{us}$ & $0-4$ p.u. \\
\hline
\end{tabular}

\section{POWER ANOMALY EFFECTS}

\section{A. Transients}

Transients, or surges, are classified as either impulsive or oscillatory, each of which is further divided into subcategories according to magnitude, duration, and spectrum content, as shown in Table II.

Impulsive transients are induced by lightning strikes. Oscillatory transients result from the system response to a lightning impulse, or from system switching events. Both types of transients can have adverse effects on all equipment, including motors, transformers, capacitors, cables, circuit breakers, and electronic components. High magnitude and fast rise transients cause degradation of insulation, immediate dielectric breakdown, or thermal failure of components due to the high energies carried by these transients. Repeated lower magnitude transients cause slow degradation and eventual failure of insulation. Resulting component failures then lead to system faults and sustained power interruptions. Low-frequency oscillatory transients resulted from switching of power-factor correction capacitors can cause nuisance tripping of adjustable speed drives (ASD) due to overvoltage protection circuitry.

Metal aircraft fuselages effectively arrest lightning. However, tremendous lightning current $(\sim \mathrm{kA})$ may 
cause uneven ground potential and induce impulsive transients in the power system, thus disrupting system operation and damaging equipment. This is particularly problematic if the structure is made from composite materials. EMP may travel through avionics access doors or panels made from composite materials to interrupt the electrical system [5, 6], or directly interfere with antennas.

Transients due to capacitive-switching typical of utility systems are not an issue in the aircraft electric system. Switched reactive power generation units generally are unnecessary in aircraft systems.

The IEEE standard [7] provides a comprehensive review of the origins of transients, rates of occurrence, levels of voltage magnitude, waveshape, and energy etc., which can be used as a guideline for designing mitigation methods. In general, various surge suppression devices which divert the energy to ground can be appropriately applied for system protection. A rather complete bibliography - SPD-Anthology — covers surge protection devices, methods and technologies developed between 1963 and 2002; it is available online [8].

The financial costs of lightning damage are colossal. Swiss Re reports $\$ 5-6$ billion in lightning-related damages annually [9]. According to the National Lightning Safety Institute, an estimated annual loss due to lightning in the U.S. is $\$ 4-5$ billion [10]. The Institute also cites other sources to show that more than $50 \%$ of in-flight military aircraft mishaps related to weather are caused by lightning, and that lightning costs about $\$ 2$ billion annually in commercial airline operating costs and passenger delays. The factors in these estimates include nonelectric power system causes, such as lightning-induced fires, weather-delayed operations, customer compensations, etc. These estimates do not directly apply to the electric PD cost. Therefore, caution must be taken in using these estimates. The cost estimate due to switching transients alone is not available in the literature at this time.

\section{B. Voltage Variations}

Voltage variations are the most common power quality problem. Table III lists voltage variations classified according to the IEEE standard [4]. Among various power quality problems, sags and momentary interruptions account for more than $80 \%$ of all events $[11,12]$. Statistical data [13] show that for a given utility site, the average incidences of voltage sags are 66 per year and the average number of momentary interruptions is 8-9 per year. Most of these last less than $2 \mathrm{~s}$. Another survey [14] on industrial and commercial sites indicates that the voltage sags occur 17 times per month on average, 8 of which are disruptive. The rate of sags (number of sags per
TABLE III

Voltage Variations [4]

\begin{tabular}{|c|c|c|c|c|}
\hline \multicolumn{3}{|c|}{ Categories } & \multirow{2}{*}{\begin{tabular}{|c|} 
Duration \\
$0.5-30$ cycles \\
$0.5-30$ cycles
\end{tabular}} & \multirow{2}{*}{$\begin{array}{l}\text { Magnitude } \\
0.1-0.9 \text { p.u }\end{array}$} \\
\hline \multirow{3}{*}{$\begin{array}{l}\text { Short } \\
\text { Duration }\end{array}$} & Instantaneous & \begin{tabular}{|l} 
Sag \\
Swell
\end{tabular} & & \\
\hline & Momentary & $\begin{array}{l}\text { Interruption } \\
\text { Sag } \\
\text { Swell }\end{array}$ & $\begin{array}{l}0.5 \text { cycles }-3 \mathrm{~s} \\
30 \text { cycles }-3 \mathrm{~s} \\
30 \text { cycles }-3 \mathrm{~s}\end{array}$ & $\begin{array}{l}<0.1 \text { p.u. } \\
0.1-0.9 \text { p.u. } \\
1.1-1.4 \text { p.u. }\end{array}$ \\
\hline & Temporary & \begin{tabular}{|l} 
Interruption \\
Sag \\
Swell
\end{tabular} & $\begin{array}{lll}3 & \mathrm{~s}-1 & \mathrm{~min} \\
3 & \mathrm{~s}-1 & \mathrm{~min} \\
3 & \mathrm{~s}-1 & \mathrm{~min}\end{array}$ & $\begin{array}{l}<0.1 \text { p.u. } \\
0.1-0.9 \text { p.u. } \\
1.1-1.2 \text { p.u. }\end{array}$ \\
\hline $\begin{array}{l}\text { Long } \\
\text { Duration }\end{array}$ & \multicolumn{2}{|c|}{$\begin{array}{l}\text { Sustained interruption } \\
\text { Undervoltage } \\
\text { Overvoltage }\end{array}$} & 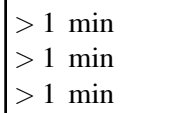 & $\begin{array}{l}0.0 \text { p.u. } \\
0.8-0.9 \text { p.u. } \\
1.1-1.2 \text { p.u. }\end{array}$ \\
\hline
\end{tabular}

month) can be estimated according to the following equation [15]:

$$
f_{\text {sag }}=\frac{0.1 \cdot V}{1-V}, \quad 0.10 \leq V \leq 0.85 \text { p.u. }
$$

where $V$ is the sag depth taking values with an increment of 0.05 p.u. Fig. 2 shows that the sag rates calculated from (1) closely match the measured sag rate. Please note that (1) and the curve in Fig. 1 are based on the data measured from distribution systems of $6 \mathrm{kV}-24 \mathrm{kV}$ lines. Caution must be taken when applying these characterizations to the effect of sags on end-use equipment, since the rate and depth of sags are dependent upon variety parameters of the system architectural and operational conditions.

The causes of short-duration voltage variations are 1) equipment failures, 2) system faults such as single line-to-ground faults due to lightning, other natural causes or human errors, 3) control system malfunction, 4) intermittent loose connections of power wiring, 5) starting of large loads, and 6) voltage transfer operation, which is specific to aircraft power systems during normal operation. Among these reasons, equipment failure and lightning are the top two ranked causes of short-duration voltage variations in terrestrial systems [15]. Depending upon the fault location and system conditions, the fault can cause three types of short-duration voltage variations; either temporary voltage rises (swells), voltage drops (sags), or a complete loss of voltage (interruptions). Fig. 3 shows the typical voltage waveform of a bus transfer operation in aircraft.

The effects of short-duration sags vary and depend on the depth of sag. Sags can drop out relays, contactors, and solenoids used in control systems [16], trip a dc-link, affect power components used in ASDs and programmable logic controllers (PLCs) [13, 17], or trigger any fault-detection circuitry used in system and utilization equipment, resulting in disruptions and loss of data. Momentary interruptions can cause electronic equipment misoperation, shutdown, and, in 


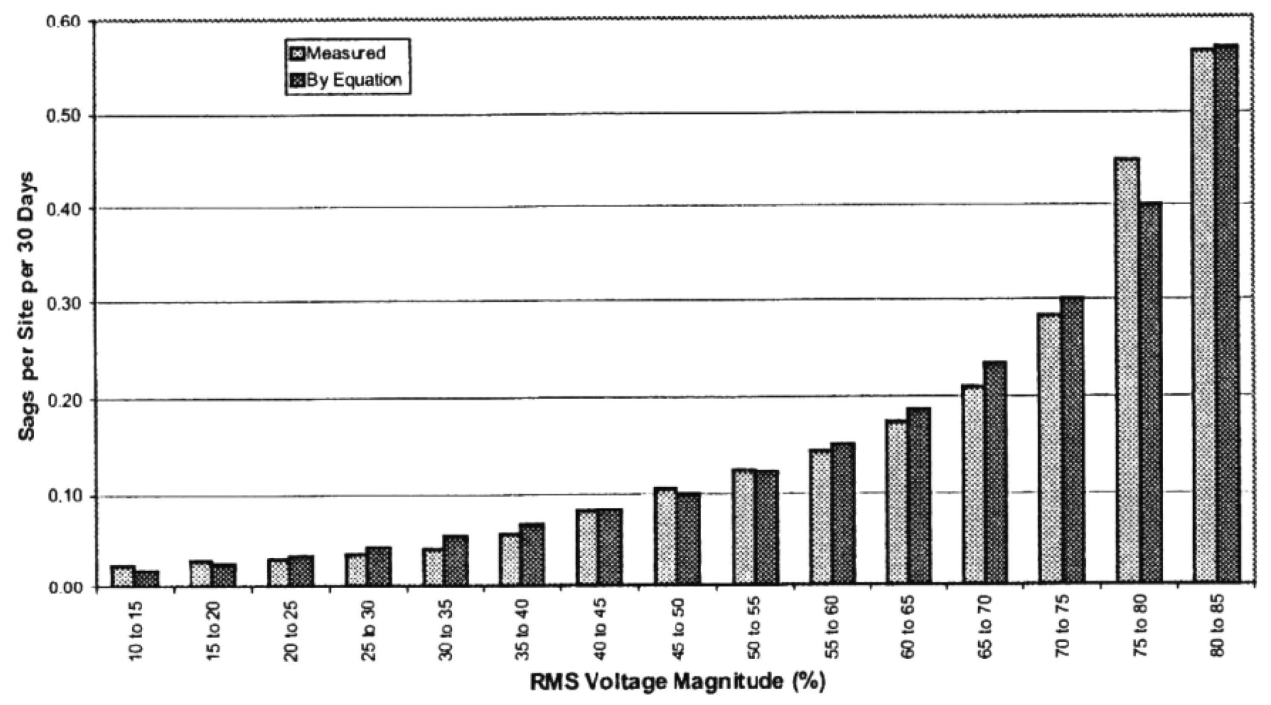

Fig. 2. Sag rate per site per month, courtesy of EPRI [15].

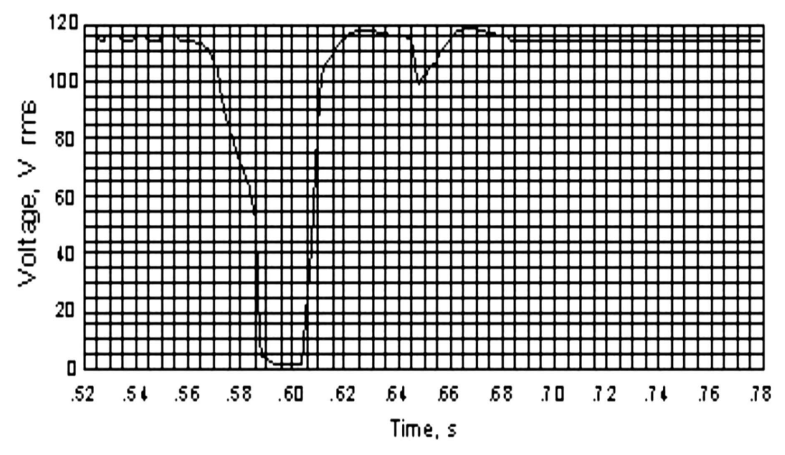

Fig. 3. Typical voltage waveform during voltage transfer operation in aircraft power system.

some cases, damage. A recent study [18] indicates that sags and momentary interruptions may be the root causes for a large percentage of unexplained equipment field failures. The most likely cause of damage is the current surges that accompany voltage sag recovery, which result in increased heating, insulation degradation, or failures in motors, transformers, and power electronics in system and load equipment.

Less common than the other two types of voltage variation, swells can cause failure of electronic devices in avionics, ASDs, and PLCs, etc., and reduced life of rotary machinery, transformers, cables, bus, switchgears, and gas discharge lamps.

Another category of variation, long-duration voltage variations occur when the ANSI limits [19] are exceeded for greater than $1 \mathrm{~min}$. The causes are 1) load variations, 2) incorrect tap setting on transformers, 3) system switching operations, and 4) tripped breakers, blown fuses, and failed circuit components. Long-duration voltage variation includes sustained interruptions, undervoltage, and overvoltage.

The effect of sustained interruptions is operation shutdown of equipment. Undervoltage can cause malfunction, dropout, and even shutdown of equipment. Undervoltage also results in motor overheating and reduced output of lighting equipment. Overvoltage can cause immediate failure of electronic devices and accelerated aging of power system equipment. It can also trigger protective devices and disrupt operation.

There are many developed technologies for voltage variation mitigations $[13,20]$. The most commonly used devices include 1) ferroresonant or constant voltage transformers, 2) uninterruptible power supplies (UPS), 3) battery or supercapacitor regulation [21], 4) tap changing regulators, 5) dip proof inverters, 6) static voltage compensators, 7) written pole motor/generators, and 8) superconducting magnetic energy storage (SEMS), etc. The capabilities of the methods to mitigate voltage variations differ significantly, each having its own limitations. An IEEE standard [22] can be used as the guideline for designing mitigation methods for sensitive equipment. For aircraft applications, the weight, physical dimensions, and cost of the applicable device and the criticality of equipment to which the device is applied must be considered. As shown in Fig. 1, the UPS and battery backup are used to improve the reliability of power supplies to the most critical aviation equipment. Due to their light-weight and high-power densities, supercapacitors are potentially useful for aircraft applications for ride-through of sags and momentary interruptions.

Voltage variations, especially sags and interruptions, cause significant loss to digital economy and industrial processes. In aircraft, power interruptions to the control system and avionics can cause loss of flight data, system malfunction, and disruption of operation, which may lead to disasters. The cost data for voltage variations are usually aggregated with outages (sustained interruptions) and transients $[1,23]$, which, according to EPRI, ranges 


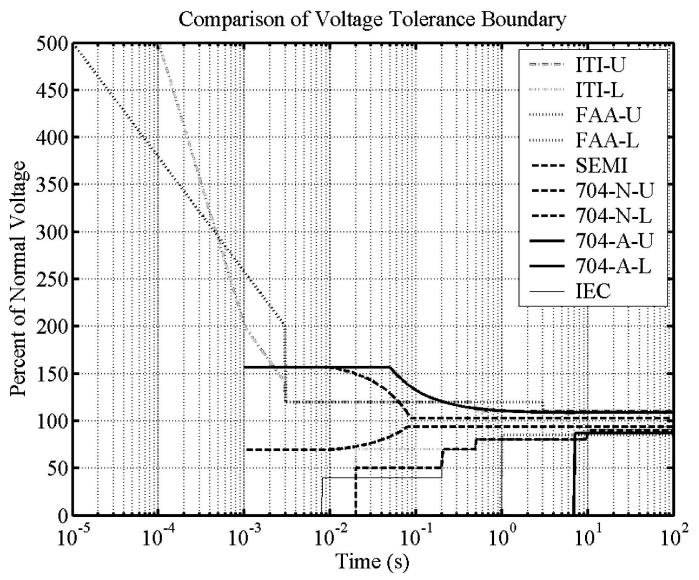

Fig. 4. Comparison of standard voltage tolerance boundaries.

from $\$ 104$ billion to $\$ 164$ billion a year in the U.S. The cost estimates for some specific systems or events $[24,25]$ also appear in the literature but will not be discussed here.

The voltage variation ride-through capability of equipment is an important measure for government and industry equipment procurement. Many equipment voltage tolerance standards have been developed for that purpose. The ITI (CBEMA) curve by Information Technology Industry Council (ITI) [26] and SEMI F47 by Semiconductor Equipment Manufacturing International (SEMI) [27] are among the most recognized. In the semiconductor manufacturing industry, sag ride-through is critical to material growth and IC chip production. SEMI F47 is thus a more stringent standard for equipment procurement compared with the ITI curve. The Federal Aviation Administration also has its own standard [28]. A comparison of these standards is shown in Fig. 4. Also shown in Fig. 4 are the aircraft electric power system $400 \mathrm{~Hz} 115 \mathrm{~V}$ short- and long-duration voltage variation tolerances [29]. In this figure the following notations are used: ITI-ITI (CEBMA) curve; SEMI-SEMI F47; FAA-FAA-G-2100G; 704-MIL-STD-704F; U-upper boundary; L-lower boundary; $\mathrm{N}$-normal; and A-abnormal.

Note that the curves 704-N and 704-A are for both power system and load equipment tolerance. Depending upon the criticality of equipment, MIL-STD-704F requires the equipment to maintain operation without disruption, dropout without losing data, or dropout without damage under the conditions of voltage transfer and abnormal operation. MIL-STD-704F requires the most critical equipment to tolerate $\sim 50 \mathrm{~ms}$ interruptions (as shown in Fig. 3) during special normal operations such as voltage transfers, and up to $7 \mathrm{~s}$ of undervoltage in abnormal operation conditions, during which time the most critical equipment must not be disrupted. Notice also that the ITI curve and FAA curve include transient tolerance, whereas MIL-STD-704F does not apply to transient tolerance. Instead, subcycle voltage spikes are covered under MIL-STD-461D, the military EMI specifications [30].

For internationally traded product and equipment, the dominant standards are those set forth by International Electrotechnical Commission (IEC), which cover the entire spectrum of electromagnetic compatibility (EMC) tests. For the voltage tolerance standards, IEC 61000-4-11 [31] and IEC 61000-4-34 [32], the equipment immunity testing and measurement standards for voltage dips (equivalent to the IEEE standard terminology sags), short interruptions, and voltage variations form ac inputs, are more widely used. Electrical and electronics equipment exporting to European community must conform to these standards to obtain a CE marker, literally indicating a European conformity. IEC 61000-4-11 and -34 are a pair of standards that apply to the equipment rated up to and above $16 \mathrm{~A}$, respectively. In terms of the tolerance on the depth and duration of dips, the IEC standards use slightly different specifications compared with SEMI F47. Above $200 \mathrm{~ms}$, IEC 61000-4-11 and -34 are essentially the same as SEMI F47; below $200 \mathrm{~ms}$, IEC imposes a more stringent requirement. The comparison of IEC 61000-4-11 and -34 to other standards is also shown in Fig. 4. It should be pointed out that to implement the equipment immunity standards, appropriate testing and measurement procedures are important. An in-depth discussion on the approaches and procedures of evaluating equipment sensitivity to voltage dips is provided in [33].

\section{Waveform Distortion}

Waveform distortions are steady-state disturbance phenomena. Transients do not belong to this category even though they too distort waveforms. Waveform distortion includes, according to IEEE STD 1159-1995, dc offset, harmonics, interharmonics, notching, and broadband noise. The dc offset can result from geomagnetic disturbances, half-wave rectification, unbalanced 3-phase loads, or system faults. The military standard [29] restricts use of half-wave rectifiers in any aircraft utilization equipment. dc offsets can cause abnormal tripping of relays, contactors, switchgears, and fault-protection circuitry $[34,35]$, thus leading to operation disruption. dc offsets can also result in flux saturation and added heating and stress in motors, transformers, and magnetic-activated devices such as relays, contactors, and solenoids. Notching is caused by power electronics switching. Deep notching can upset the state of digital electronics and affect the timing circuitry that uses zero-crossings.

The most prominent and also troublesome waveform distortion is harmonics, which is also one 
TABLE IV

Harmonic Current Generation from Equipment

\begin{tabular}{|c|c|c|c|c|}
\hline \multicolumn{3}{|c|}{ Equipment } & THD & Harmonics \\
\hline \multirow{3}{*}{ System } & \multicolumn{2}{|c|}{ Generator and transformer } & & Due to flux saturation or mechanical reasons, relatively small voltage harmonics \\
\hline & $3 \phi \mathrm{TRU}$ & $\begin{array}{l}\text { 6-pulse (CS) } \\
\text { 6-pulse (VS) } \\
\text { 12-pulse }\end{array}$ & $\begin{array}{l}24-30 \% \\
30-67 \% \\
10-20 \%\end{array}$ & $\begin{array}{l}\text { 5th, } 7 \text { th, } 11 \text { th }, 13 \text { th }, 17 \text { th }, \ldots[41,42] \\
5 \text { th, } 7 \text { th }, 11 \text { th }, 13 \text { th }, 17 \text { th }, \ldots[41,42] \\
11 \text { th, } 13 \text { th }, 23 \text { rd }, \ldots[43,44]\end{array}$ \\
\hline & \multicolumn{2}{|c|}{$\begin{array}{l}1 \phi \text { Switched mode PS } \\
\text { Rectifier PS } \\
\text { Digital PS } \\
\text { Phase-controlled converter }\end{array}$} & $\begin{array}{l}70-90 \% \\
70 \% \\
38 \% \\
0-140 \%\end{array}$ & $\begin{array}{l}\text { All odd harmonics } \\
\text { All odd harmonics } \\
\text { DC, 3rd predominant, }[45] \\
\text { Varies with firing angle }[38,42]\end{array}$ \\
\hline Load & \multicolumn{2}{|c|}{$\begin{array}{l}\text { ASD } \\
\text { PC or computer systems } \\
\text { Printer } \\
\text { Oscilloscope } \\
\text { Fluorescent Lamps } \\
\text { Search radar or HF radio }\end{array}$} & $\begin{array}{l}42-140 \% \\
58-115 \% \\
82.4 \% \\
63.5 \% \\
15-20 \% \\
8-12 \%\end{array}$ & $\begin{array}{l}\text { All odd harmonics [46] } \\
\text { DC, all odd harmonics [46, 47] } \\
\text { DC (60\%), all harmonics up to } 30 \text { th, [45] } \\
\text { DC, high 2nd, 3rd, 5th, significant } 4 \text { th, 9th, [45] } \\
\text { Predominant 3rd, [45] } \\
\text { (loads to 12-pulse TRU) } 11 \text { th, } 13 \text { th,... [48] }\end{array}$ \\
\hline
\end{tabular}

of the most dynamic research areas in industry and academia. More than a third of our collected literature on power disturbances concerns harmonics. This is because harmonics cause reduced utilization capacity and reliability of electric power systems; these issues become more critical as the use of power electronics loads increases [36]. In aircraft, nearly $20 \%$ to $30 \%$ loads are nonlinear. Therefore, harmonic control is one of the key issues in aircraft electric power quality. Another issue yet to be addressed is the effect of a much higher fundamental ac frequency $(400 \mathrm{~Hz})$ and its harmonics in aircraft systems, compared with $50 / 60 \mathrm{~Hz}$ in terrestrial systems, for which little research can be found in the literature.

There are two landmark reviews on harmonics by IEEE task forces $[37,38]$. These reviews outline the causes and effects of harmonics. The latest version of the IEEE standard [39] provides harmonic control guidelines for both harmonic voltage and current, whereas the previous version [40] deals only with harmonic voltages. The update reflects the advances of research in both the electric power and equipment manufacturing industries from 1981 to 1993. However, since then there has been an explosive use of office, residential, and industrial nonlinear loads. In addition, many traditional linear devices such as motors and lighting equipment have changed to nonlinear versions due to the use of electronic power conversion and control systems. In order to address the issue, significant research on mitigation technology for terrestrial $50 / 60 \mathrm{~Hz}$ systems has been done in the last two decades to characterize system reliability due to harmonic effects and its related economic impact.

In aircraft electric power systems, there is a trend towards increased use of nonlinear loads also. All nonlinear loads draw distorted sinusoidal currents containing harmonic content. Due to finite bus and source impedances, the voltage waveforms at buses or sources become distorted, thus polluting the entire system. Harmonic generation in aircraft results from two classes of sources: 1) nonlinear load equipment, and 2) power system equipment. Table IV lists harmonic generation from some typical equipment. Except for generators and transformers, the harmonic content and the total harmonic distortions (THDs) listed in Table IV refer to their current distortion for all other equipment. The levels of harmonic content and THD depend on particular equipment and its design.

Table V summarizes the effects of voltage and current harmonics on equipment. As can be seen, almost all equipment is affected. In particular, the overall system reliability is severely reduced due to component accelerated aging, premature failure, malfunction, and disruption. Several studies variously characterize the life expectation of components under the effect of voltage and current harmonics. For example, incandescent lamps lose $47 \%$ of the useful life if the harmonic voltage is $105 \%$ of the normal [38]; the useful motor life will be cut in half for every $8^{\circ} \mathrm{C}$ temperature increase due to harmonic current [49]; another study [50] indicates that in the presence of both harmonic voltage and current, electrical stress is the dominant factor in reducing the life of energy components. Under multi-stresses, the life of motors is reduced to $54 \%-59 \%$, cables $48 \%$, and capacitors $40 \%$. The effect of voltage distortion on aging acceleration under partial discharge activity is discussed by Fabiani and Montanari [51]. In military aircraft, controlling harmonics (both conducted and radiated) from power leads is specified in the standard MIL-STD-461D [33]. MIL-STD-704F does not impose specific limits on current harmonics, but does require that, when the aircraft designer has finished the complete system, the voltage distortion be limited to $5 \%$ plus a distortion spectrum limit for individual frequency components of voltage distortion. 
TABLE V

Effects of Harmonics

\begin{tabular}{|c|c|}
\hline Effect and Symptom & Equipment \\
\hline $\begin{array}{l}\text { 1. Increased reactive power burden-Harmonic loading, low } \\
\text { power factor, capacity derating }\end{array}$ & $\begin{array}{l}\text { System components: generators, transformers, motors, and } \\
\text { cables, buses, circuit breakers, capacitors, etc. }\end{array}$ \\
\hline 2. Decreased efficiency-Increased thermal loss & All system and load equipment \\
\hline $\begin{array}{l}\text { 3. Accelerated aging and premature failure-Thermal overloading, } \\
\text { distorted voltage stress, insulation deterioration }\end{array}$ & $\begin{array}{l}\text { Generators, motors, transformers, capacitors, cables and power } \\
\text { electronics components, incandescent and gas discharge lamps }\end{array}$ \\
\hline $\begin{array}{l}\text { 4. Reduced reliability-Increased equipment and component } \\
\text { malfunction and disruption }\end{array}$ & $\begin{array}{l}\text { Relays, contactors, fuses, circuit breakers, fault-protection } \\
\text { circuitry, zero-crossing timing circuitry, peak sensing circuitry }\end{array}$ \\
\hline 5. Reduced stability & $\begin{array}{l}\text { Motor torque pulsating, mechanical resonance, light output } \\
\text { variations }\end{array}$ \\
\hline 6. Communication interference-Noise, cross talk, disruption & $\begin{array}{l}\text { Communication and wireless controlled equipment (stray } \\
\text { coupling with harmonic emissions) }\end{array}$ \\
\hline
\end{tabular}

The effectiveness of harmonic mitigation methods applied to a commercial office building is discussed by Key and Lai [52, 53]. The model for the building electric power system is similar to an aircraft electric power system in many ways except that it is connected to a power grid. It includes the following major equipment: 1) a distribution transformer (600 kVA); 2) a service entrance (main bus $480 \mathrm{~V}, 16 \% \mathrm{THD}$ ) connecting to $1 \phi$ and $3 \phi$ large linear and nonlinear loads (ASD, $277 \mathrm{~V}$ lighting, UPS, large computers, 50-150\% THD), and to a service transformer (480/208 V, 30\% THD); 3 ) a subpanel or load center ( $120 \mathrm{~V}$ panel, $90 \%$ THD); 4) and multiple branch circuits or cord connections (computers, etc. 100\% THD). The paper concludes that the most effective approach to eliminate harmonics is a built-in power-factor correction circuit or a boost converter inside electronic equipment. The next best option is using various harmonic filters, of which the location is critical for reducing losses. Namely, the parallel-connected resonant filter (PCRF) and series-connected resonant filter (SCRF) are recommended for branch circuit or cord connected level near the load equipment. These filters are cost effective and in most cases the combination of PCRF and SCRF is used to block more harmonics. The neutral current filter (ZCF), zigzag filter (ZZF), and active power filter (APF) are suggested for subpanel or load center level. The ZCF and ZZF work best for eliminating triplens and reducing the neutral current. The neutral current primarily consists of zero-sequence harmonics (3rd order harmonic and its triplens (9th, 15th, $21 \mathrm{st}, \ldots))$. Zero-sequence harmonics are principally the by-product of switched-mode power supply technology which is used in avionics, motor drives, lighting systems, and in virtually all other low-power electronic devices. These harmonics do not cancel but rather add up in the neutral conductor, which causes overheating of the neutral conductor.
The harmonic cost and mitigation benefits are also characterized by Key and Lai [53, 54]. Using a similar building system with four types of cables (500 kcmil, 4/0, 1/0 and 12 AWG) and detailed harmonic loss model, the total harmonic loss of cables and transformers is $4,802 \mathrm{~W}$ for every $60 \mathrm{~kW}$ load, and the yearly added cost is $\$ 2,101$. This rationale can be used to estimate the total harmonic loss in the U.S. In the year 1997, the net electricity generation is 3492.2 billion $\mathrm{kWh}$ [55]. This yields an averaged power generation of about $398.7 \mathrm{GW}$. The lost generation due to harmonics is then $31.91 \mathrm{GW}$, and the added cost is $\$ 13.96$ billion for the year 1997 . Assuming the same cost ratio applies in the year 2001, the harmonics loss would have been $\$ 14.94$ billion (the net electricity generation is 3736.6 billion $\mathrm{kWh}$ in 2001). In terms of the rationale of military spending to the U.S. GDP, the annual added cost due to harmonics in military electric power installations is $\$ 716.3$ million for the year 2001. Note that the calculation is for cable and transformer harmonic loss only. It does not include the aging and failure cost of load equipment, and does not account for the power loss from load equipment. It should be pointed out that the model used by Key and Lai is a commercial building typically with a high concentration of nonlinear loads, which may not be applicable to an industrial site where the majority of loads are ac motors. Therefore, the estimate of the cost due to harmonics needs to be improved by assessing the differences of the nonlinear loads percentage in various end-user facilities compared with those of a commercial building.

\section{Voltage Imbalance}

Voltage imbalance, or unbalance, can result from unbalanced $3 \phi$ loads due to unevenly distributed single-phase loads, from malfunctions of automatic power-factor correction equipment and voltage 


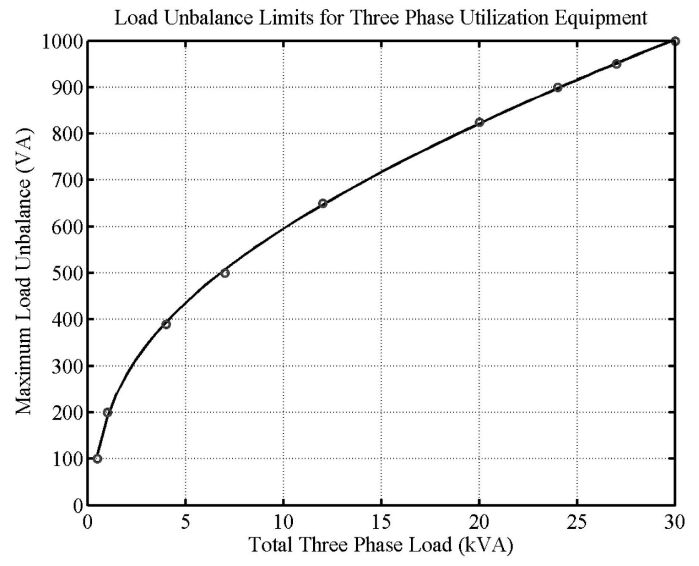

Fig. 5. MIL-STD-704F load unbalance limits.

regulators in the distribution lines, from unbalanced transformer or capacitor banks (caused by blown fuses), or from unequal lengths of $3 \phi$ cables. The primary concern of voltage imbalance is the heating effect on motors [56]. Voltage imbalance results in additional negative-sequence current circulating in motor rotors. Every $1 \%$ voltage imbalance results in five to six times the percent of current imbalance. Current imbalance can be as high as nine times the voltage imbalance. Combined voltage imbalance and harmonic distortion can result in significant life loss of motors [57]. For example, for a $100 \mathrm{HP}$ motor, the life reduction is $43.8 \%$ for $9 \%$ THD harmonics and $1 \%$ voltage imbalance. It is $53.4 \%$ if the voltage imbalance increases to $2 \%$. The estimated capital cost due to loss of useful life of motors in the U.S. is $\$ 2.8$ billion for combined effects of $1 \%$ imbalance and 9\% THD, or $\$ 4.75$ billion if the voltage imbalance increases to $2 \%$.

In order to limit the voltage imbalance in military aircraft power systems, MIL-STD-740F requires that a load of a capacity larger than $0.5 \mathrm{kVA}$ must use a $3 \phi$ source, and the load imbalance must satisfy the limits shown in Fig. 5. Currently, MIL-STD-704F allows a maximum of a $3.0 \mathrm{~V}$ voltage imbalance (115 V line-to-neutral nominal) for user equipment, which is equivalent to about $2.6 \%$ imbalance in the IEEE standard. IEEE recommends $0.5 \%-2 \%$ voltage imbalance [58], while NEMA recommends a limit of $1 \%$ [59]. It might be beneficial to further study the voltage imbalance limit in MIL-STD-704F compared with the IEEE and NEMA standards, so that the impact of the $3.0 \mathrm{~V}$ voltage imbalance limit on the system and load equipment in military aircrafts can be revealed, and the methods of reducing the level of imbalance can be discovered.

\section{E. Power Frequency Variation}

Power frequency variation is not an issue in terrestrial grid-connected utility systems because large capacity generators are operated in parallel and maintained under close control. However, aircraft generators are of relatively small capacities, and the likelihood of frequency change is high. The frequency change, including variations and fluctuations (modulations), results from unbalanced dynamics between load and generation capacity, which may be caused by adding up or disconnecting large loads in an electric system, or by a disturbance torque, such as due to wind gust, at an engine or a generator. Electric system faults or speed control system instability also cause frequency variations or fluctuations. The equipment that is sensitive to power frequency variations includes rotary machinery and that equipped with zero-crossing timing-circuitry. A slight variation of electric power frequency may cause damage of rotary machine shafts, while the timing-circuitry depending upon the zero-crossings of fundamental frequency may be upset. MIL-STD-704F strictly controls both variations and modulations of system power frequency to ensure safe and normal operation of power system and load equipment. The key issue in power frequency variation mitigation is to improve control system performance such as system dynamic response, steady-state accuracy, and immunity to disturbances.

\section{F. Static Charge}

Static buildup in aircraft during flight missions due to atmospheric electricity can interfere with antenna operation. In addition, static corona discharge at sharp tips or spark discharge between unbounded metal sections $[5,6]$ can cause structure surface damage which may be further corroded due to moisture in air. Static can be safely discharged once the aircraft lands on ground.

\section{CONCLUSION}

This paper provides a review of the literature and a summary of the effects and costs of power disturbances specific to LV military autonomous electric power systems. The following conclusions can be drawn.

1) Terrestrial and aircraft electrical system anomaly share some similarities, but there are differences. Specifically, voltage transfer occurs normally in aircraft and causes voltage interruptions. Frequency variation is more likely to occur in aircraft systems, but not in terrestrial grid-connected systems due to parallel operation of large generators in the latter. In addition, disturbances in de distribution systems are also unique to aircraft systems.

2) In terrestrial electric systems, the most common electric anomalies are voltage sags and interruptions, which cause disruption and failure of equipment such as electronics and motors. The total loss due to power disturbances, including equipment damage, material loss, idled labor, and lost production or sales, 
costs the U.S. economy $1.2 \%$ to $1.9 \%$ of its GDP, or \$119-\$188 billion a year (in 2001 dollar value).

3) In aircraft electric systems, electric anomalies damage user equipment such as avionics and motors, and disrupt system operation, which may lead to aircraft fatalities. Using the rationale of the military spending to the GDP, it is estimated that the electric anomalies cost the DOD about \$5.8-9.2 billion a year (in the 2001 dollar value). To improve the estimate, the detailed military equipment capital costs, the PD sensitivity, the PD frequency of occurrence in the military systems, and other consequent costs resulted from PD effects must be studied and taken into account.

4) Harmonic pollution is a serious concern for the electric system reliability and economy. Harmonics result in reduced system capacity, accelerated component aging and premature failure, and reduced efficiency. It is estimated that the power loss due to harmonics in cables and transformers is $31.4 \mathrm{GW}$ and an annual added cost to the U.S. economy is \$14.94 billion (in 2001). Equivalently, it costs the DOD about $\$ 716.3$ million a year due to harmonic loss in military electric power installations in 2001. Again, to improve the estimation, harmonic characteristics must be studied in military electric systems. In particular, the effects due to a higher system fundamental frequency $(400 \mathrm{~Hz})$ and its harmonics in aircraft electric power systems should be thoroughly investigated to address the issue.

5) Voltage imbalance tolerance $(2.6 \%)$ in MIL-STD-704F is slightly out of the IEEE recommended value range $(0.5-2 \%)$. Voltage imbalance can cause considerable motor heating and resultant loss of useful life. $53.4 \%$ of the useful life of a 100-HP motor is lost for the combined effects of $9 \%$ THD and $2 \%$ voltage imbalance. The estimated capital cost due to motor life loss in the U.S. is $\$ 4.75$ billion under the same effects. It will be beneficial to conduct further studies to investigate the effects of the voltage imbalance tolerance in MIL-STD-704F compared with the IEEE and NEMA standards.

6) Finally, characterization of all electric anomalies in military electric systems such as those in aircrafts, naval ships, and land-based military vehicles should be conducted to better determine the effects and costs, so that appropriate mitigation methods and technologies can be developed and applied for reducing the life cycle cost of equipment.

\section{REFERENCES}

[1] EPRI

The cost of power disturbances to industrial and digital economy companies.

EPRI Technical report 1006274, June 2001.

[2] Bureau of Economic Analysis (BEA)

BEA News.

BEA 04-36, http://www.bea.doc.gov/bea/newsrelarchive/ 2004/gdp204a.pdf, retrieved on Sept. 2, 2004.
[3] CDI

2001-2002 Military Almanac.

http://www.cdi.org/products/almanac0102.pdf, retrieved on Sept. 1, 2004.

[4] IEEE Standards Board

IEEE Recommended Practice for Monitoring Electric Power Quality.

IEEE STD 1159-1995, June 1995.

[5] Braidotti, V., Zaninelli, D., and Zanini, A. Power quality studies on aircraft electric systems. In Proceedings of Ninth International Conference on Harmonics and Quality of Power, vol. 2, Oct. 2000, 625-632.

[6] Faranda, R., Zaninelli, D., and Zanini, A. Electric power quality on aircraft: Analysis and propagation of disturbances.

IEEE Power Engineering Society Summer Meeting, vol. 1, July 2001, 222-227.

[7] IEEE Standards Board

IEEE Surge Protection Standards Collection. IEEE STD C62-1992, 1992.

[8] Martzloff, F

Surge protection in low-voltage AC power circuits-An anthology.

NISTIR 6714-1, http://www.eeel.nist.gov/811/spdanthology/AnnotatedBibliography.pdf, Dec. 2002, retrieved on Sept. 10, 2004.

[9] Swiss Re

Twister! The professional reinsurer's perspective. Sigma report 1/2000, Swiss Re, Zurich, 2000

[10] Kithil, R.

Results of investigations into annual USA lightning costs and losses.

National Lightning Safety Institute, Louisville, CO, http://www.lightningsafety.com/nlsi_lls/nlsi_annual_usa losses.htm, retrieved on Sept. 10, 2004.

[11] Gomez, J., Morcos, M., Reineri, C., and Campetelli, G. Behavior of induction motor due to voltage sags and short interruptions.

IEEE Transactions on Power Delivery, 17, 2 (Apr. 2002), 434-440.

[12] Gomez, J., and Morcos, M

Voltage sag and recovery time in repetitive events. IEEE Transactions on Power Delivery, 17, 4 (Oct. 2002), 1037-1043.

[13] PIER/EPRI

Voltage-sag solutions for industrial customers. EPRI report 1007485, Palo Alto, CA, California Energy Commission, Sacramento, CA, Jan. 2003.

[14] Koval, D., and Hughes, M.

Canadian national power quality survey: Frequency of industrial and commercial voltage sags.

IEEE Transactions on Industry Applications, 33, 3 (May/June 1997), 622-627.

[15] EPRI

Distribution system power quality assessment: Phase II: Voltage sag and interruption analysis.

EPRI Technical report 1001678, Mar. 2003.

[16] Pohjanheimo, P., and Lehtonen, M.

Equipment sensitivity to voltage sags-test results for contactors, PCs and gas discharge lamps.

In Proceedings of the 10th International Conference on Harmonics and Quality of Power, vol. 2, Oct. 2002, 559-564.

[17] PIER/EPRI

Characterizing the impact of power quality on programmable logic controller with and without power-conditioning devices.

EPRI report 1001072, Palo Alto, CA, California Energy Commission, Sacramento, CA, Oct. 2000 
Bendre, A., Divan, D., Kranz, W., and Brumsickle, W. Equipment failure caused by power quality disturbances. Presented at the IEEE 39th IAS Annual Meeting Conference record CD 04CH37569C, Seattle WA, Oct. 2004.

[19] ANSI American National Standards for Electric Power Systems and Equipment-Voltage ratings $(60 \mathrm{~Hz})$. ANSI C84.1-1989, 1989.

[20] Degeneff, R., Barss, R., Carnovale, D., and Raedy, S. Reducing the effect of sags and momentary interruptions: a total owning cost prospective. In Proceedings of Ninth International Conference on Harmonics and Quality of Power, vol. 2, Oct. 2000, 397-403.

[21] Kazimierczuk, M., and Cravens, R. Application of super capacitors for voltage regulation in aircraft distributed power systems.

In Proceedings of the 27th Annual IEEE Power Electronics Specialists Conference (PESC '96 Record), vol. 1, June 1996, 835-841.

[22] IEEE Guide for Service to Equipment Sensitive to Momentary Voltage Disturbances.

IEEE STD 1250-1995, June 1995.

[23] Lawton, L., Sullivan, M., Van Liere, K., Katz, A., and Eto, J.

A framework and review of customer outage costs: Integration and analysis of electric utility outage cost surveys.

Lawrence Berkeley National Laboratory report LBNL-54365, Nov. 2003.

[24] Koval, D., Beristain, J., and Bent, D. Evaluating the reliability cost of computer system interruptions due to power system disturbances. IEEE Transactions on Industry Applications, 25, 2 (Mar./Apr. 1989), 248-256.

[25] Eto, J., Koomey, J., Lehman, B., Martin, N., Mills, E., Webber, C., and Worrel, E.

Scoping studies on trends in the economic value of electricity reliability to the U.S. economy.

Lawrence Berkeley National Laboratory report

LBNL-47911, June 2001.

[26] Information Technology Industry Council (ITIC) ITI (CEBMA) curve application note. http://www.itic.org/technical/iticurv.pdf. Retrieved on Sept. 15, 2004.

[27] Power Standards Lab (PSL) http://www.powerstandards.com/SEMIF47.htm. Retrieved on Sept. 15, 2004.

[28] Federal Aviation Administration Specification: Electronic Equipment, General Requirements.

Federal Aviation Administration, Department of Transportation, FAA-G-2100G, Oct. 2001. http://www.faa.gov/asd/standards/faa-g-2100g.pdf. Retrieved on Sept. 15, 2004.

[29] MIL-STD-704F

Aircraft electric power characteristics.

Department of Defense Interface Standard, Mar. 2004.

[30] MIL-STD-461D

Requirements for the control of electromagnetic interference emissions and susceptibility.

Department of Defense Interface Standard, Jan. 1993.

[31] IEC 61000-4-11

Electromagnetic compatibility (EMC)-Part 4-11:

Testing and measurement techniques-Voltage dips, short interruptions and voltage variations immunity tests. Ed. 2.0, Mar. 2004.
[32] IEC 61000-4-34

Electromagnetic compatibility (EMC)—Part 4-34: Voltage dips, short interruptions and voltage variations immunity tests for equipment with input more than 16 A per phase. CDV, July 2004.

[33] Stephens, M., McGranaghan, M., and Bollen, M. Evaluating voltage dip immunity of industrial equipment. Appeared as an online multimedia presentation at http://www.f47testing.com/voltage_dip_immunity.html. Retrieved on Aug. 25, 2005.

[34] Chapman, F., and Hammonds, B.

The effect of dc offset on instantaneous operating characteristics of low-voltage circuit breakers. IEEE Transactions on Industry Applications, 33, 6 (Nov./Dec. 1997), 1488-1492.

[35] Stringer, N.

The effect of dc offset on current-operated relays. IEEE Transactions on Industry Applications, 34, 1 (Jan./Feb. 1998), 30-34.

[36] Redl, R., Tenti, P., and Daan van Wyk, J. Power electronics' polluting effects. IEEE Spectrum, 34, 5 (May 1997), 32-39.

[37] IEEE Task Force

The effects of power system harmonics on power system equipment and loads.

IEEE Transactions on Power Apparatus and Systems,

PAS-104, 9 (Sept. 1985), 2555-2563.

[38] Wagner, V., Balda, J., Griffith, D., McEachern, A., et al. Effects of harmonics on equipment.

IEEE Transactions on Power Delivery, 8, 2 (Apr. 1993), 672-680.

[39] IEEE Recommended Practices and Requirements for Harmonic Control in Electric Power Systems. ANSI/IEEE STD 519-1992, 1992.

[40] IEEE Guide for Harmonic Control and Reactive Compensation of Static Power Converters. ANSI/IEEE STD 519-1981, Apr. 1981.

[41] Rice, D.

A detailed analysis of six-pulse converter harmonic currents.

IEEE Transactions on Industry Applications, 30, 2 (Mar./Apr. 1994), 294-304.

[42] Melhorn, C., and McGranaghan, M. Interpretation and analysis of power quality measurements.

IEEE Transactions on Industry Applications, 31, 6 (Nov.-Dec. 1995), 1363-1370.

[43] Gong, G., Drofenik, U., and Kolar, J. 12-pulse rectifier for more electric aircraft applications. In Proceedings of IEEE International Conference on Industrial Technology, vol. 2, Dec. 2003, 1096-1101.

[44] Andrews, D., Bishop, M., and Witte, J. Harmonic measurements, analysis, and power factor correction in a modern steel manufacturing facility. IEEE Transactions on Industry Applications, 32, 3 (May/June 1996), 617-624.

[45] Sharma, V., Moinuddin, M., Doja, Ibraheem and M. Khan Power quality assessment and harmonic comparison of typical nonlinear electronic loads.

In Proceedings of the IEEE International Conference on Industrial Technology, vol. 1, Jan. 2000, 729-734.

[46] Briggs, S., Savignon, D., Krein, P., and Kim, M. The effects of nonlinear loads on EMI/RFI filters. IEEE Transactions on Industry Applications, 31, 1 (Jan.-Feb. 1995), 184-189. 
[47] Mansoor, A., Grady, W., Staats, P., Thallam, R., Doyle, M., and Samotyj, $\mathrm{M}$.

Predicting the net harmonic currents produced by large numbers of distributed single-phase computer loads.

IEEE Transactions on Power Delivery, 10, 4 (Oct. 1995), 2001-2006.

[48] Ferland, G., Chikhani, A., and Cartier, J.

Harmonic and transient analysis of an aircraft electrical distribution system.

In Proceedings of the Canadian Conference on Electrical and Computer Engineering, vol. 2, Sept. 1993, 668-671.

[49] Inan, A., and Attar, F.

The life expectancy analysis for an electric motor due to harmonics.

In Proceedings of the 9th Mediterranean Electrotechnical Conference (MELECON'98), vol. 2, May 1998, 997-999.

[50] Caramia, P., Carpinelli, G., Verde, P., Mazzanti, G.,

Cavallini, A., and Montanari, G.

An approach to life estimation of electrical plant components in the presence of harmonic distortion. In Proceedings of 9th International Conference on Harmonics and Quality of Power, vol. 3, Oct. 2000, 887-892.

[51] Fabiani, D., and Montanari, G.

The effect of voltage distortion on ageing acceleration of insulation systems under partial discharge activity. IEEE Electrical Insulation Magazine, 17, 3 (May/June 2001), 24-33.

[52] Key, T. S., and Lai, J-S.

Comparison of standards and power supply design options for limiting harmonic distortion in power systems. IEEE Transactions on Industry Applications, 29, 4 (July/Aug. 1993), 688-695.

[53] Lai, J-S., and Key, T. S.

Effectiveness of harmonic mitigation equipment for commercial office buildings.

IEEE Transactions on Industry Applications, 33, 4

(July/Aug. 1997), 1104-1110.
[54] Key, T. S., and Lai, J-S.

Costs and benefits of harmonic current reduction for switch-mode power supplies in a commercial office building.

IEEE Transactions on Industry Applications, 32, 5

(Sept.-Oct. 1996), 1017-1025.

[55] Energy Information Administration (EIA).

Annual energy review

2002. http://www.eia.doe.gov/aer/pdf/pages/sec8_8.pdf. Retrieved on Sept. 14, 2004.

[56] Kersting, W.

Causes and effects of unbalanced voltages serving an induction motor.

IEEE Transactions on Industry Applications, 37, 1 (Jan./Feb. 2001), 165-170.

[57] de Abreu, J., and Emanuel, A.

Induction motor thermal aging caused by voltage distortion and imbalance: Loss of useful life and its estimated cost.

IEEE Transactions on Industry Applications, 38, 1 (Jan./Feb. 2002), 12-20.

[58] IEEE Standards Board

IEEE Recommended Practice for Electric Power

Distribution for Industrial Plants (Red Book). ANSI/IEEE STD 141-1993, 1993.

[59] National Electrical Manufacturers Association (NEMA) Standard for Motors and Generators.

National Electrical Manufacturers Association, NEMA MG-1, 1993. 


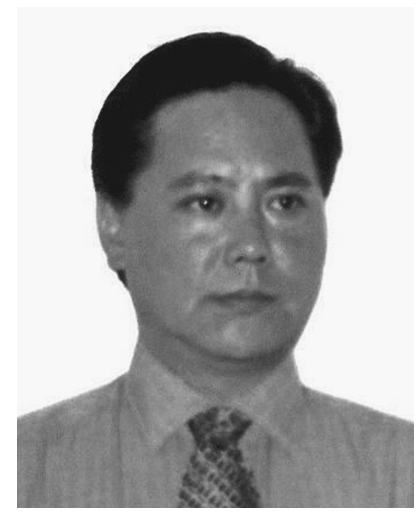

Shengyi Liu (S'94-M'96-SM'02) received the Ph.D. in electrical engineering in 1995 from the University of South Carolina, Columbia.

He was senior research and development engineer at InnerLogic, Inc. from 1995-1999, and is now research associate professor in the Department of Electrical Engineering at the University of South Carolina. His research interests include design and development of energy storage technologies, renewables, physical electronics-based devices, power semiconductor devices and converters; energy efficiency and power quality improvement in autonomous power systems; distributed power generation for the future energy network; and modeling and simulation of interdisciplinary systems.

Dr. Liu is a licensed professional engineer in the State of South Carolina, and a Member of AIAA.

Charles H. Singer received the B.S. degree in electrical engineering, University of Maryland, College Park, in 1987.

He was project engineer, Electric Power Systems, NSWCCD/Annapolis, from 1988-1995, project engineer, Electrical Power Systems, NAVAIR from 1995-1997, and senior project engineer, Electrical Power Systems, NAVAIR from 1997-2004. From 1997 to the present, as senior electrical project engineer. Mr. Singer has been responsible for the full life cycle systems engineering management and systems integration of aircraft electrical power systems. He is team technical leader for the development of arc fault circuit breakers for military and commercial aircraft under ONR Future Naval Capabilities, Total Ownership Cost Program.

Mr. Singer is a member of the Society of Automotive Engineers.

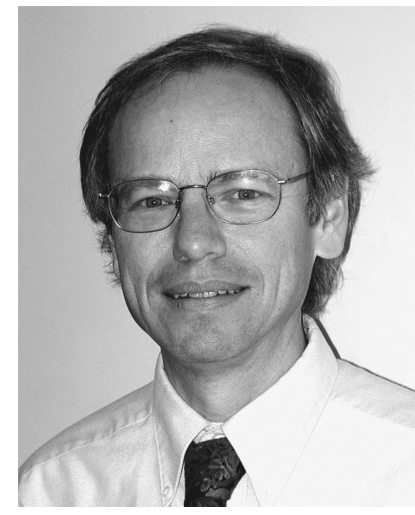

Roger A. Dougal (S'74-M'82-SM'94) received the Ph.D. degree in electrical engineering at Texas Tech University, Lubbock, in 1983.

He joined the faculty at the University of South Carolina in 1983 where he is now the Director of the Virtual Test Bed project. His research interests include pulsed power systems, especially plasma-based switching devices, and electron beam generation and applications, and laser systems and electro-optics.

Dr. Dougal received the Samuel Litman Distinguished Professor of Engineering award, and has been honored as a Carolina Research Professor. 